\title{
Freude und Aktivität
}

Mich freut es, wenn sich eins ins andere fügt und sich rund anfühlt. So erging es mir kürzlich, als ich mich mit der neuen Leitlinie Demenzen beschäftigte. Bei Klienten mit leichter bis mittelschwerer Demenz empfehlen Experten nun ergotherapeutische Maßnahmen ( $\odot$ Seite 6). Sie erachten zudem individualisierte Verfahren, die Freude und Aktivität fördern, als wichtig.

Für diese Aspekte zu sensibilisieren, war ein Herzensanliegen von Helga Rohra am 10. ergotag in Stuttgart. Vor neun Jahren erhielt sie die Diagnose Lewy-Körperchen-Demenz. Für die damalige Konferenzdolmetscherin, die mit neun Sprachen jonglieren konnte, brach eine Welt zusammen, doch eine neue begann. Inzwischen ist sie als engagierte Aktivistin für Menschen mit Demenz viel unterwegs. Das braucht sie, denn ein voller Kalender war auch wichtiger Teil ihres vorherigen Lebens. Hart arbeitet sie daran, die Demenz am Fortschreiten zu hindern. Dank ihrer Logopädin spricht sie perfekt und ausdrucksstark. Dank ihrer Ergotherapeutin erledigt sie wichtige Dinge des täglichen Lebens selbst und führt ein selbstbestimmtes Leben. Die allergrößte Leistung der Ergotherapeutin

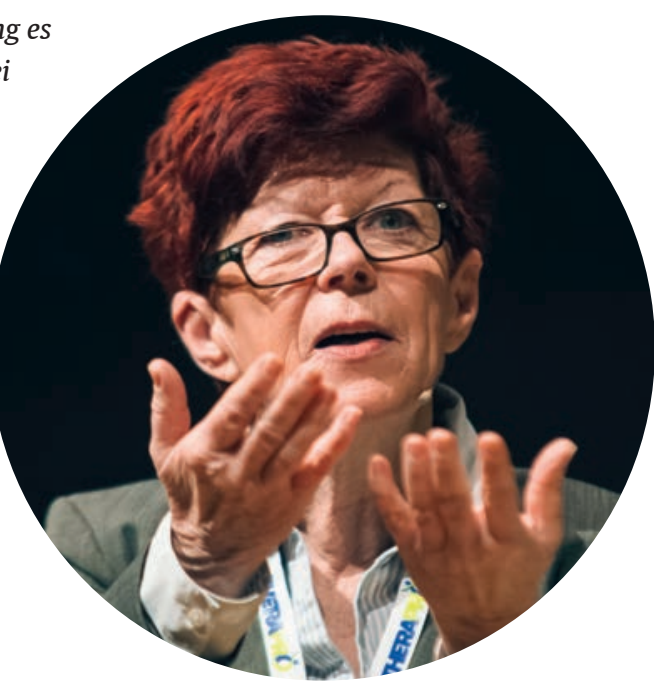
jedoch war: Helga Rohra zu befähigen, mit ihrem Hund an einem Wettkampf teilzunehmen. Das gemeinsame Arbeiten mit der Ergotherapeutin und dem Tier brachte ihr Freude und Aktivität

Helga Rohra in ihrem Element. Sie engagiert sich für eine ressourcenorientierte Sichtweise auf Menschen mit Demenz. - und einen vollen Terminkalender. Das zählte für sie mehr als der erste Platz, den sie und ihr Hund gemeinsam erkämpften.

Herzlichst

Ihre
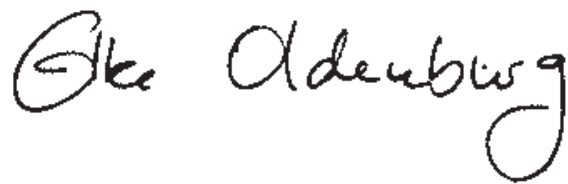